\title{
PENDIDIKAN ISLAM DALAM PEMBENTUKAN KEPRIBADIAN ISLAMI SANTRI PESANTREN SABILUNNAJAT CIAMIS
}

\section{ISLAMIC EDUCATION IN THE FORMATION OF ISLAMIC PERSONALITY, SANTRI PESANTREN SABILUNNAJAT CIAMIS}

\author{
${ }^{1)}$ Andriyani, ${ }^{2)}$ Abul A'la Al Maududi, ${ }^{3)}$ Triana Srisantyorini, ${ }^{4}$ Tata Hari Umara, ${ }^{5}$ Devi Syafira \\ ${ }^{1,2,3,4,5)}$ Program Studi Kesehatan Masyarakat, Fakultas Kesehatan Masyarakat \\ Universitas Muhammadiyah Jakarta \\ Jalan KH. Ahmad Dahlan, Cirendeu, Ciputat. \\ Email : drandriyanimag@gmail.com
}

\begin{abstract}
ABSTRAK
Pembentukan kepribadian Islami merupakan ciri dari generasi muslim. Di Indonesia meskipun mayoritas pendudukanya muslim, namun belum mencerminkan kepribadian islami. Salah satu kelompok penduduk yang berperan penting dalam kemajuan masyarakat muslim adalah para santri yang jumlahnya terus meningkat. Tujuan dari kegiatan Pengabdian kepada Masyarakat ini adalah untuk membentuk kepribadian islami pada Santri di Madrasah Sabilunnajat Ciamis, Jawa Barat. Metode yang digunakan dalam Pengabdian masyarakat ini berupa pendidikan Islami dari fasilitator kepada santri. Hasil dari pelaksanaan kegiatan pengabdian masyarakat ini adalah santri akan dapat mengintegrasikan pengetahuan yang diperoleh melalui madrasah formal dengan pengetahuan agama yang diperoleh melalui pendidikan pesantren dalam kehidupan sehari-hari. Pendidikan Islami ini diharapkan dapat diterapkan pada seluruh santri di wilayah Ciamis Jawa Barat pada khususnya dan dapat direplikasi secara menyeluruh pada santri-santri di Indonesia.
\end{abstract}

Kata Kunci : Pengabdian Masyarakat, Pendidikan Islam, Kepribadian Islami

\begin{abstract}
The formation of an Islamic personality is a feature of the Muslim generation. In Indonesia, although the majority of its occupation is Muslim, it does not yet reflect Islamic personality. One of the population groups that has an important role in the progress of Muslim societies is the number of students. The purpose of this Community Service activity is to establish an Islamic personality of students at Pesantren Sabilunnajat Ciamis, West Java. The method used in this community service was in the form of Islamic education from the facilitator to the students. The result of the implementation of community service activities was students will be able to integrate the knowledge gained through formal madrasa with religious knowledge obtained through pesantren education in daily life. Islamic education is expected to be applied to all students in the Ciamis region of West Java in particular and can be replicated as a whole to students in Indonesia.
\end{abstract}

Keywords : Community services, education of islam, Islamic Personality. 


\section{PENDAHULUAN}

Pesantren adalah institusi islam tertua yang tumbuh di Indonesia dan memiliki peran yang sangat penting dalam sejarah Indonesia. Di pesantren, santri memperoleh bimbingan berkelanjutan di sepanjang waktu dan mencakup semua dimensi. Hal ini didukung oleh fakta bahwa sekolah asrama adalah lembaga pendidikan tradisional tempat para santri tinggal bersama dan belajar sains di bawah bimbingan kiai (Guru Islam), dan memiliki tempat di mana santri harus tinggal. Tempat ini memfasilitasi kepala pesantren, kiai dan guru untuk dapat memantau akhlak mereka sepanjang waktu karena kiai dan santri tinggal di daerah yang sama. Selain itu, pengembangan karakter juga didukung oleh ketersediaan masjid di area sekolah sebagai sarana ibadah, ruang untuk membaca, dan kegiatan keagamaan lainnya. Hal lain yang mendukung disiplin dan kontrol kegiatan santri, di sekitar sekolah, biasanya membangun benteng yang mencegah keluar masuknya santri secara bebas. Karena itu, mereka terbiasa mengikuti setiap kegiatan keagamaan, resital atau hafalan dan kegiatan keagamaan lainnya (Suhartini, 2016).

Pondok pesantren adalah lembaga pendidikan tradisional Islam untuk mempelajari, memahami,mendalami, menghayati dan mengamalkan ajaran Islam dengan menekankan pentingnya moral keagamaan sebagai pedoman perilaku sehari-hari. Ajaran Islam tersebut menyatu dengan struktur kontekstual atau realitas sosial yang digumuli dalam kehidupan keseharian (Sulaiman, 2016). Pesantren merupakan lembaga pendidikan Islam yang memiliki akar historis yang cukup kuat sehingga menduduki posisi relatif sentral dalam dunia keilmuan. Dalam masyarakatnya, pesantren sebagai sub kultur lahir dan berkembang seiring dengan perubahan-perubahan dalam masyarakat global. Selain itu, salah satu lembaga pendidikan yang mempunyai kekhasan tersendiri dan berbeda dengan lembaga pendidikan yang lainnya (Firdaus and Wekke, 2017).

Banyaknya lembaga pendidikan yang ada di Indonesia mencerminkan betapa seriusnya pemerintah untuk memajukan taraf pendidikan di Indonesia. Jumlah lembaga pendidikan yang sangat banyak di Indonesia seharusnya membentuk karakter siswa peserta didik yang baik serta mencerminkan akhlak-akhlak terpuji, namun seiring dengan berjalannya waktu, banyak kasus yang tidak terpuji terjadi belakangan ini. Di Indonesia, tawuran antar pelajar semakin meningkat, serta bentuk-bentuk kenakalan remaja lainnya terutama di kota-kota besar, pemerasan/kekerasan (bullying), kecenderungan dominasi senior terhadap junior, penggunaan narkoba, dan lain-lain (Zulhijrah, 2017). Hal ini membuat kesenjangan antara proses pembelajaran dan pendidikan karakter di sekolah dengan perilaku siswa yang ada. Maka dari itu kelompok pengabdian masyarakat tertarik untuk melakukan kegiatan pengabdian masyarakat untuk mengetahui lebih lanjut tentang kepribadian islami melalui pendidikan di Pesantren Sabilunnajat, Ciamis.

Pembentukan kepribadian Islami adalah pembentukan kepribadian yang diarahkan kepada peningkatan dan pengembangan faktor dasar (bawaan) dan faktor ajar (lingkungan), dengan berpedoman kepada nilai-nilai keislaman. Faktor dasar pengembangan dan peningkatan kemampuannya melalui bimbingan dan pembiasaan berfikir, bersikap dan bertingkah laku menurut norma-norma Islam. Sedangkan faktor ajar dilakukan dengan cara mempengaruhi individu melalui proses dan usaha membentuk kondisi yang mencerminkan pola kehidupan yang sejalan dengan norma-norma Islam seperti teladan, nasihat, anjuran, ganjaran, pembiasaan, hukuman, dan pembentukan lingkungan serasi (Harahap, 2019).

Pesantren Sabilunnajat di Ciamis merupakan salah satu pesantren yang memiliki santri yang cukup banyak. Di Pesantren Sabilunnajat, santri selain diberikan pendidikan formal seperti pendidikan di sekolah pada umumnya, mereka juga dibekali pendidikan agama. Pengabdian masyarakat dilakukan di Pesantren Sabilunnajat dikarenakan adanya kekhawatiran 
kelompok pengabdian masyarakat mengenai kemungkinan munculnya kesenjangan antara proses pembelajaran dan pembentukan kepribadian islami santri.

\section{METODE}

Pengabdian masyarakat dilaksanakan di Pesantren Sabilunnajat, Ciamis, Jawa Barat pada Bulan Februari 2020. Sasaran dilaksanakannya kegiatan pengabdian masyarakat adalah para santri di Pesantren Sabilunnajat yang berjumlah 205 orang. Adapun media dan alat pendukung yang digunakan antara lain melalui ceramah dari fasilitator mengenai pentingnya pendidikan Islami terhadap pembentukan karakter Islami santri, kemudian santri mendengarkan dan menyimak penjelasan dari fasilitator. Selain itu santri di Pesantren Sabilunnajat juga diberikan Al-Qur'an dengan terjemahan, guna menunjang kemampuan santri dalam melakukan tafsir ayat-ayat Al-Qur'an. Adapun mitra dalam pelaksanaan kegiatan pengabdian masyarakat ini adalah Pesantren Sabilunnajat dan Fakultas Kesehatan Masyarakat Universitas Muhammadiyah Jakarta.

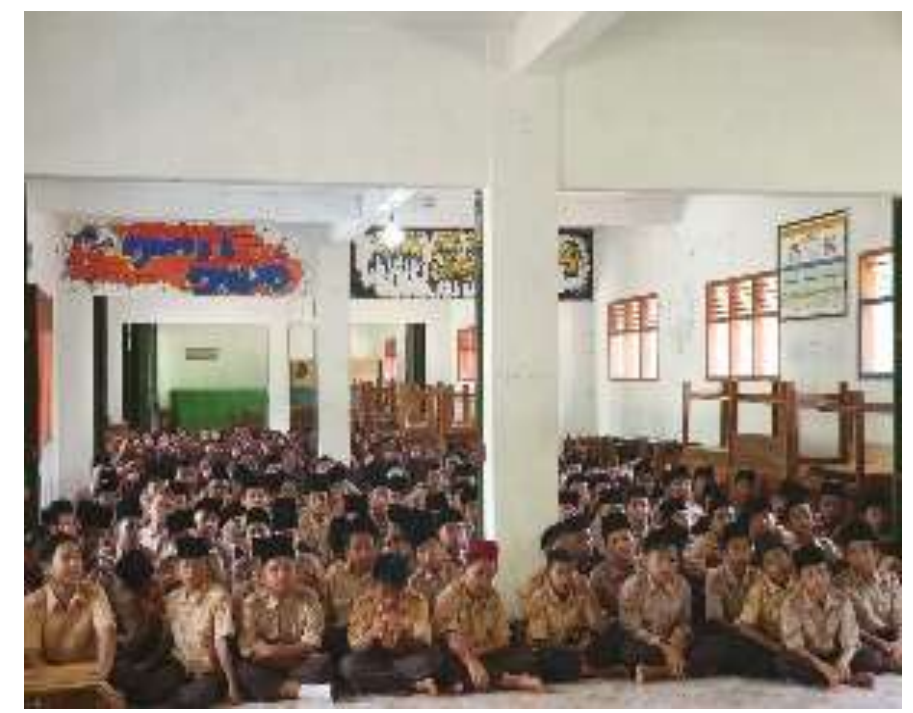

Sumber: Dokumentasi primer, 2020

Gambar 1. Santri Menyimak Penjelasan Mengenai Pendidikan Islami

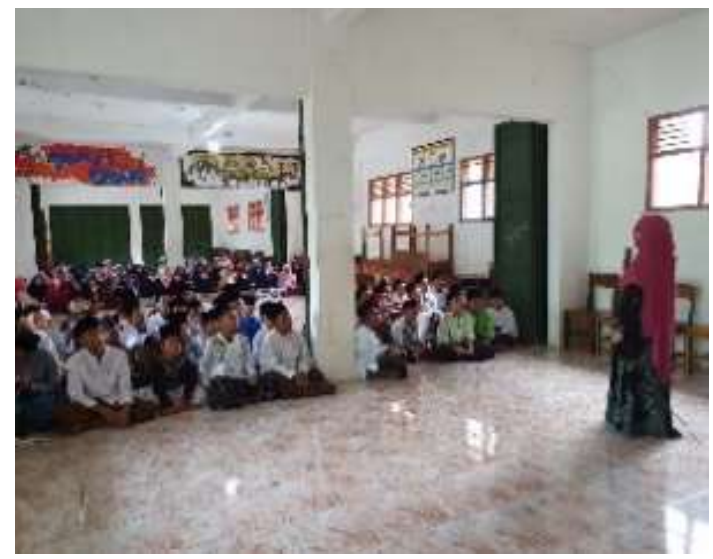

Sumber: Dokumentasi primer, 2020

Gambar 2. Fasilitator Menjelaskan Pentingnya Pendidikan Islami dalam Pembentukan Kepribadian Islami 
Sumber: Dokumentasi primer, 2020

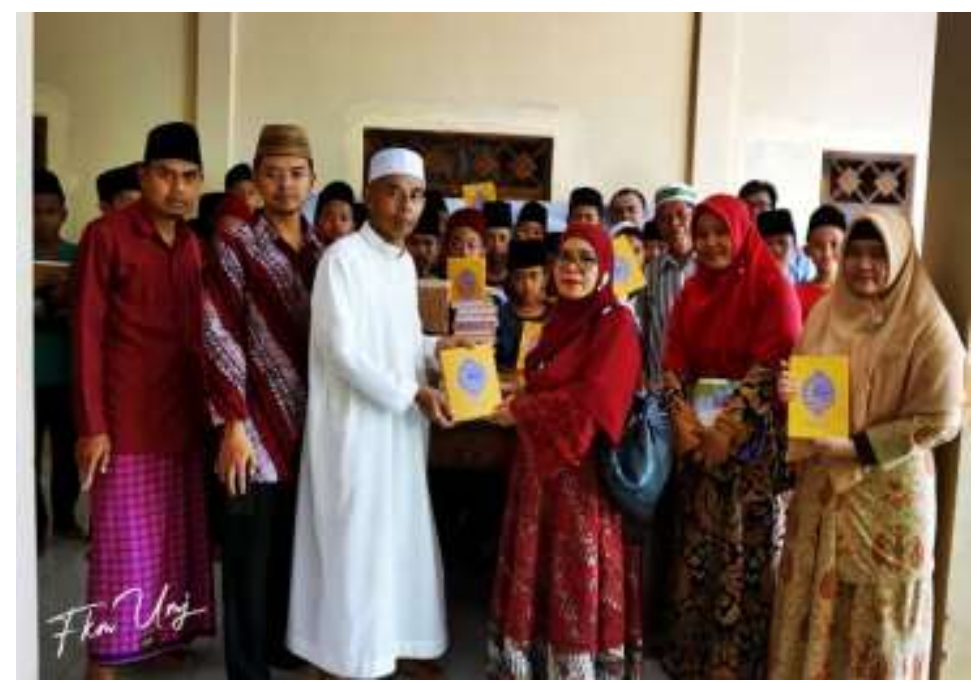

Gambar 3. Pemberian Al-Qur'an untuk Para Santri Pesantren Sabilunnajat

\section{HASIL DAN PEMBAHASAN}

Hasil dari pelaksanaan kegiatan pengabdian masyarakat ini adalah santri mampu memahami pentingnya pendidikan Islami dalam pembentukan kepribadian Islami mereka. Santri akan dapat mengintegrasikan pengetahuan yang diperoleh melalui madrasah formal dengan pengetahuan agama yang diperoleh melalui pendidikan pesantren dengan buku-buku kuningnya dalam kehidupan sehari-hari. Pengetahuan ini akan memudahkan siswa untuk memahami makna hidup yang sebenarnya. Hidup mandiri, terpisah dari orang tua, fasilitas apa adanya, akan membentuk santri sebagai muslim yang bertanggung jawab dan terbiasa memotivasi diri untuk menjadi lebih baik (Muntholib, Maisah and Maryani, 2018).

Dari perspektif ilmu pendidikan, pedagogi pesantren sangat relevan diimplementasikan dalam sistem pendidikan nasional dengan mempertimbangkan fakta bahwa pendidikan adalah agen tradisi yang menghormati nilai-nilai dan adat istiadat dan ilmu yang dapat merekayasa kemanusiaan dan budaya strategi dalam menciptakan masyarakat yang beradab dan layak (Ma'Arif, 2018). Sebagai lembaga pendidikan, pesantren tidak hanya mendidik para santri untuk mempelajari ilmu agama saja, melainkan juga membekalinya dengan akhlak yang menjadi karakter khas dari seorang santri, sehingga tidak salah jika menganggap bahwa pesantren dapat pula disebut sebagai lembaga pendidikan Islam yang membangun karakter (Siregar, 2018).

Temuan ini dapat dijadikan referensi untuk semua sekolah yang belum memiliki mata pelajaran agama islam untuk dijadikan sumber bacaan karena ternyata mata pelajaran agama islam memberikan pengaruh terhadap pembentukan kepribadian islami siswa. Hal ini diharapkan kepribadian islami siswa Indonesia dapat mengurangi tindakan kriminal anak dibawah umur.

Pendidikan Islam mengacu pada masukan apa pun yang membuat individu menjadi orang yang lebih baik, baik dalam bentuk tarbiyah, ta'lim atau ma'rifah secara umum. Seorang yang berpendidikan Islam akan menjadi orang yang lebih baik dalam semua aspek; tindakannya, pemikiran, gaya hidup, pengambilan keputusan dan pendekatan untuk masalah yang mempengaruhi kehidupan secara keseluruhan. Berbeda dengan pendidikan konvensional, pendidikan Islam melibatkan nilai-nilai, spiritualitas, dan aspek etika penerima. Hal ini membentuk pola pikir, karakter dan cara berpikir (Sudan, 2017). 
Hal ini sejalan dengan apa yang tertuang dalam Al-Qur'an Surat Al-Mujadilah Ayat 11

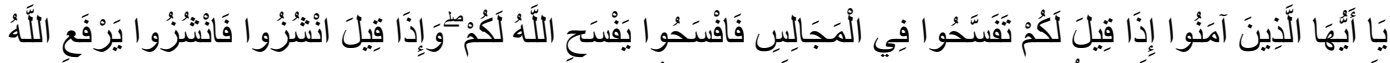

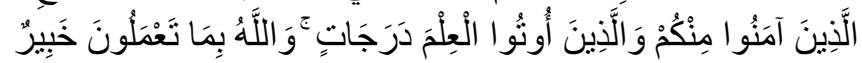

Artinya : Hai orang-orang beriman apabila dikatakan kepadamu: "Berlapanglapanglah dalam majlis", maka lapangkanlah niscaya Allah akan memberi kelapangan untukmu. Dan apabila dikatakan: "Berdirilah kamu", maka berdirilah, niscaya Allah akan meninggikan orang-orang yang beriman di antaramu dan orang-orang yang diberi ilmu pengetahuan beberapa derajat. Dan Allah Maha Mengetahui apa yang kamu kerjakan.

Implementasi pendidikan karakter dalam Islam juga tercermin dalam karakter pribadi Rasulullah SAW yang juga tertian dalam Al-Qur'an dalam surat Al-Ahzab ayat 21, yaitu :

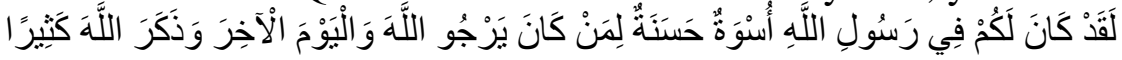

Artinya : Sesungguhnya telah ada pada (diri) Rasulullah itu suri teladan yang baik bagimu (yaitu) bagi orang yang mengharap (rahmat) Allah dan (kedatangan) hari kiamat dan dia banyak menyebut Allah.

Akhlak terpuji merupakan perhiasan umat Islam maka dari itu bagi setiap santri memiliki akhlak terpuji adalah impiannya. Sebagai bekal yang bersifat fitri, setiap manusia memiliki potensi yang bersifat netral antara kebaikan dan keburukan. Fitrah ini merupakan kemampuan dasar yang mengandung peluang untuk berkembang yang bergantung pada proses pendidikan yang diterimanya (Rizal, 2018).

\section{KESIMPULAN DAN SARAN}

Pendidikan Islami yang dilakukan oleh kelompok pengabdian masyarakat kepada santri di Pesantren Sabilunnajat sangat penting dalam pembentukan karakter Islami santri. Dengan adanya pendidikan Islami serta pendidikan karakter, maka akan dapat mengurangi kesenjangan yang terjadi di pesantren pada umumnya, yaitu kesenjangan antara pendidikan formal dengan pendidikan karakter. Hasil dari pengabdian masyarakat ini juga dapat dijadikan referensi untuk penelitian selanjutnya dan diharapkan menjadi bagian dalam membentuk peradaban yang berakhlak terpuji.

\section{UCAPAN TERIMA KASIH}

Kami ingin mengucapkan banyak terimakasih kepada semua pihak yang telah menyukseskan acara pengabdian masyarakat ini. Terkhusus untuk pengurus pesantren Sabilunnajat Ciamis.

\section{DAFTAR PUSTAKA}

Firdaus and Wekke, I. S. 2017. Pattern of Pesantren On Expanding of Smart, Hardworking and Ikhlas Characters in West Suamtera, Seminar Pendidikan Transdisiplin (STEd 2017), (STEd), pp. 258-265.

Harahap, A. M. 2019. Pembentukan Kepribadian Muslim dalam Perspektif Filsafat Pendidikan Islam. Studi Multidisipliner, 6(1), pp. 46-64.

Ma'Arif, S. 2018. Education as a foundation of humanity: Learning from the pedagogy of pesantren in Indonesia. Journal of Social Studies Education Research, 9(2), pp. 104-123. doi: 10.17499/jsser.58854.

Muntholib, Maisah and Maryani. 2018. Management of Pesantren in Development of Islamic Religion Education in Jambi Province. International Journal of Research Granthaalayah, 6(9), pp. 407-420. doi: 10.5281/zenodo.1451886.

Rizal, S. 2018. Jurnal Edukasi Islami Jurnal Pendidikan Islam. Vol . 07 / No . 1, Teori-Teori 
Pendidikan ... Teori-Teori Pendidikan ...', Jurnal Pendidikan Islam, 07(1), pp. 23-46. doi: 10.30868/EI.V7.

Siregar, A. S. 2018. Sejarah Perkembangan Sistem Pendidikan Islam di Pesantren Ar-Raudlatul Hasanah Kota Medan. JUSPI (Jurnal Sejarah Peradaban Islam), 2(1), pp. 113-123.

Sudan, S. A. 2017. The Nature of Islamic Education. American International Journal of Contemporary Research, 7(3), pp. 22-27. doi: 10.1177/0263276407074997.

Suhartini, A. 2016. The Internalization of Islamic Values in Pesantren. Jurnal Pendidikan Islam, 2(3), p. 429. doi: 10.15575/jpi.v2i3.827.

Sulaiman, R. 2016 .Pendidikan Pondok Pesantren: Institusionalisasi Kelembagaan Pendidikan Pesantren. 'Anil Islam: Jurnal Kebudayaan dan Ilmu Keislaman, 9(1), pp. 148-174. Available at: http://jurnal.instika.ac.id/index.php/AnilIslam/article/view/12.

Zulhijrah. 2017. Implementasi Pendidikan Karakter Di Sekolah', Tadrib: Jurnal Pendidikan Agama Islam, 1(1), pp. 118-136. Available at: http://jurnal.instika.ac.id/index.php/AnilIslam/article/view/12. 